\title{
ALK Rearrangement Analysis Was Performed
}

National Cancer Institute

\section{Source}

National Cancer Institute. ALK Rearrangement Analysis Was Performed. NCI Thesaurus.

Code C160318.

An indication that ALK rearrangement analysis was performed during the study. 